\title{
Soundscape monitoring acoustic data collected in July of 2017 during an in situ larval coral settlement experiment in St. John, US Virgin Islands
}

Website: https://www.bco-dmo.org/dataset/742573

Data Type: Other Field Results

Version: 1

Version Date: 2018-07-27

\section{Project}

" Coral Chorus: The Role of Soundscapes in Coral Reef Larval Recruitment and Biodiversity (Coral Chorus)

\begin{tabular}{|l|l|l|}
\hline Contributors & Affiliation & Role \\
\hline Apprill, Amy & Woods Hole Oceanographic Institution (WHOI) & $\begin{array}{l}\text { Principal Investigator, } \\
\text { Contact }\end{array}$ \\
\hline $\begin{array}{l}\text { Mooney, T. } \\
\text { Aran }\end{array}$ & Woods Hole Oceanographic Institution (WHOI) & Co-Principal Investigator \\
\hline$\underline{\text { Lillis, Ashlee }}$ & Woods Hole Oceanographic Institution (WHOI) & Scientist \\
\hline$\underline{\text { York, Amber }}$ & $\begin{array}{l}\text { Woods Hole Oceanographic Institution (WHOI } \\
\text { BCO-DMO) }\end{array}$ & BCO-DMO Data Manager \\
\hline
\end{tabular}

\begin{abstract}
Matlab R2016 was used to process acoustic data from raw wave audio files. Mean power spectral densities were estimated (Hamming window, non-overlapping 0.5-sec windows, frequency resolution: $1.47 \mathrm{~Hz}$ ) within 1-minute samples across the total experiment length (62 hours).
\end{abstract}

\section{Table of Contents}

- Coverage

- Dataset Description

- Acquisition Description

- Processing Description

- Related Publications

- Parameters

- Instruments 
- Deployments

- Project Information

- Funding

\section{Coverage}

Spatial Extent: N:18.31789 E:-64.72218 S:18.30962 W:-64.76065

Temporal Extent: 2017-07-25 - 2017-07-27

\section{Dataset Description}

This dataset contains audio files and mean power spectral densities (PSD). See the "Data Files" section to download files by site.

The related dataset "Coral settlement" contains coral settlement data where these audio recordings were collected.

Coral settlement: https://www.bco-dmo.org/dataset/742565

\section{Acquisition Description}

SoundTrap (ST-300, Ocean Instruments NZ) acoustic recorders were deployed to continuously record at $48 \mathrm{kHz}$ sampling frequency from 25-27 July, 2017. Recorders were positioned approximately $0.5 \mathrm{~m}$ above the seafloor.

Sites:

Tektite Reef (18.30962N, 64.72218W)

Cocoloba Reef (18.31528N, 64.76065W)

OffReef $(18.31789 \mathrm{~N}, 64.75059 \mathrm{~W})$ - A sand site with no reef structure within $100 \mathrm{~m}$

Soundscape and habitat characterization:

Acoustic recordings were analyzed to compare the experimental soundscapes, first by examining acoustic spectra (sound power as a function of frequency). Mean power spectral densities were estimated (Hamming window, non-overlapping 0.5-sec windows) within 1minute samples across the total experiment length (62 hours). Root-mean-square (rms) sound pressure levels (SPL; dB re 1Pa) were calculated for each site in the 1-minute samples, within two frequency bands of interest. The lower analysis band (50-1000 Hz) contains the majority of fish-produced acoustic signals, as well as noise generated by wind and waves, while the higher analysis band (1000-20000 Hz) primarily represents the acoustic energy derived from invertebrate sounds (e.g., snapping shrimp). Because reef soundscapes exhibit diel variability, 
spectrograms were produced to further detect acoustic differences between sites.

Benthic cover and fish diversity and abundance at the sites were characterized during July 2017 using visual surveys as previously described (Kaplan et al. 2015). Benthic surveys included six $10 \mathrm{~m}$ long, $1 \mathrm{~m}$ wide transects, with benthic cover recorded every $10 \mathrm{~cm}$. For fish, three $30 \mathrm{~m}$-long, $2 \mathrm{~m}$-wide video transects were performed, with fish enumerated and identified. Fish abundances were calculated as the total number per transect, and fish species richness was the total number of species identified at each site.

\section{Processing Description}

Matlab R2016 was used to process acoustic data from raw wave audio files. Mean power spectral densities were estimated (Hamming window, non-overlapping 0.5-sec windows, frequency resolution: $1.47 \mathrm{~Hz}$ ) within 1-minute samples across the total experiment length $(62$ hours).

[ table of contents $\mid$ back to top ]

\section{Related Publications}

Kaplan, M., Mooney, T., Partan, J., \& Solow, A. (2015). Coral reef species assemblages are associated with ambient soundscapes. Marine Ecology Progress Series, 533, 93-107. doi:10.3354/meps11382

[ table of contents $\mid \underline{\text { back to top }]}$

\section{Parameters}

Parameters for this dataset have not yet been identified

[ table of contents $\mid$ back to top ]

\section{Instruments}


Dataset-specific

Instrument Name

SoundTrap (ST-300, Ocean Instruments NZ) acoustic recorders

Generic Instrument Name

Acoustic Recorder

Generic Instrument

An acoustic recorder senses and records acoustic signals from

Description the environment.

[ table of contents $\mid \underline{\text { back to top }]}$

\section{Deployments}

\section{Coral_Chorus_St_John}

\begin{tabular}{|l|l|}
\hline Website & https://www.bco-dmo.org/deployment/748532 \\
\hline Platform & Virgin Islands \\
\hline
\end{tabular}

[ table of contents | back to top ]

\section{Project Information}

\section{Coral Chorus: The Role of Soundscapes in Coral Reef Larval Recruitment and Biodiversity (Coral Chorus)}

Coral reef ecosystems host some of the highest biodiversity of life per unit area on Earth and harbor about one quarter to one third of all marine animals. Reef-associated animals are a major source of protein for millions of people, and reefs offer shoreline protection and provide a significant source of tourism revenue, especially in developing countries. Factors that influence supply and settlement of young (larval) fish, coral, and associated animals can have large impacts on reef ecosystem and population structure, and learning more about these can help improve understanding of how to maintain the benefits provided by coral reefs. This study will lead to a detailed, mechanistic understanding of how young larvae use natural sounds to orient toward, locate, and select preferred settlement habitat. The approach will combine detailed field measurements and experiments to isolate key soundscape variables that impact coral reef larvae. For marine communities, such as those on coral reefs, factors influencing larval supply and settlement can have major impacts on community structure and population replenishment. There are now some indications that sound plays an important role in attracting larvae to suitable settlement habitat. There is little understanding of what soundscape habitat 
information is available to larvae and how differences and variability in sound can influence settlement. This project will include comprehensive experiments, environmental measurements, and modeling with the goal of understanding the role of sound in influencing larval recruitment and local biodiversity. The investigators will measure in situ settlement of larval fish and coral in relation to different soundscapes and habitat conditions in a marine protected area using traditional larval sampling methods, moored acoustic recorders, and a suite of environmental observations. Controlled and calibrated environmental playback experiments will isolate soundscape components and determine specific and fundamental acoustic cues larvae use to orient and settle. The spatial and temporal variability of soundscape cues and components across reef habitats will be established. Finally, the project will determine the relevant ranges of sound plumes that larvae may encounter through direct measurements of the sound fields of multiple reefs.

[ table of contents $\mid$ back to top ]

\section{Funding}

\begin{tabular}{|l|l|}
\hline Funding Source & Award \\
\hline NSF Division of Ocean Sciences (NSF OCE) & OCE-1536782 \\
\hline
\end{tabular}

[ table of contents | $\underline{\text { back to top ] }}$ 